https://www.journal-imab-bg.org

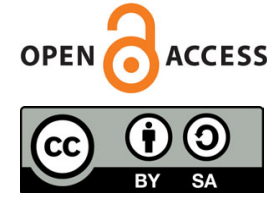

Case report

\title{
MINIMALLY INVASIVE SINGLE FLAP APPROACH WITH CONNECTIVE TISSUE WALL FOR PERI- ODONTAL REGENERATION
}

\author{
Kamen Kotsilkov \\ Department of Periodontology, Faculty of Dental Medicine, Medical University \\ - Sofia, Bulgaria.
}

\section{ABSTRACT:}

INTRODUCTION: The destructive periodontal diseases are among the most prevalent in the human population. In some cases, bony defects are formed during the disease progression, thus sustaining deep periodontal pockets.

The reconstruction of these defects is usually done with the classical techniques of bone substitutes placement and guided tissue regeneration. The clinical and histological data from the recent years, however, demonstrate the relatively low regenerative potential of these techniques.

The contemporary approaches for periodontal regeneration rely on minimally invasive surgical protocols, aimed at complete tissue preservation in order to achieve and maintain primary closure and at stimulating the natural regenerative potential of the periodontal tissues.

AIM: This presentation demonstrates the application of a new, minimally invasive, single flap surgical technique for periodontal regeneration in a clinical case with periodontitis and a residual deep intrabony defect.

MATERIALS AND METHODS: A 37 years old patient presented with chronic generalised periodontitis. The initial therapy led to good control of the periodontal infection with a single residual deep periodontal pocket medially at 11 due to a deep intrabony defect. A single flap approach with an enamel matrix derivate application and a connective tissue wall technique were performed. The proper primary closure was obtained.

RESULT: One month after surgery an initial mineralisation process in the defect was detected. At the third month, a complete clinical healing was observed. The radiographic control showed finished bone mineralisation and periodontal space recreation.

CONCLUSION: In the limitation of the presented case, the minimally invasive surgical approach led to complete clinical healing and new bone formation, which could be proof for periodontal regeneration.

Keywords: periodontal bone defect, periodontal regeneration, single flap, connective tissue wall

\section{INTRODUCTION:}

The destructive periodontal diseases are among the most prevalent in the human population. They are characterised by progressive loss of periodontal structures and could lead, eventually, to tooth loss. In some cases bony defects are formed during the progression of the disease, thus forming deep periodontal pockets, which are one of the most significant risk factors for further bone loss.

The initial mechanical periodontal therapy aims the control of the supra- and subgingival dental biofilm is the main treatment of these diseases. The scientific data show very good results in terms of infection control, but also demonstrate the limited potential to induce recovery of the formed bone defects.

The reconstruction of the periodontal bone defects, for decades, is done with the classical techniques of bone substitutes placement and guided tissue regeneration with barrier membranes. The clinical and histological data from the recent years, however, demonstrate the relatively low regenerative potential of these techniques.

The contemporary treatment approaches for periodontal regeneration rely on new, minimally invasive surgical protocols, aimed at complete tissue preservation in order to achieve and maintain primary closure during the critical stages of healing and to save space for blood clot formation and maturation, stimulating the natural regenerative potential of the periodontal tissues.

\section{MATERIALS AND METHODS:}

This presentation demonstrates the application of the connective tissue wall technique in a 37 years patients presented with chronic generalised periodontitis (Fig. 1 and 2). The clinical observation revealed a Miller III class recession on the buccal aspect of the right central maxillar incisor.

Fig. 1. Initial clinical status.

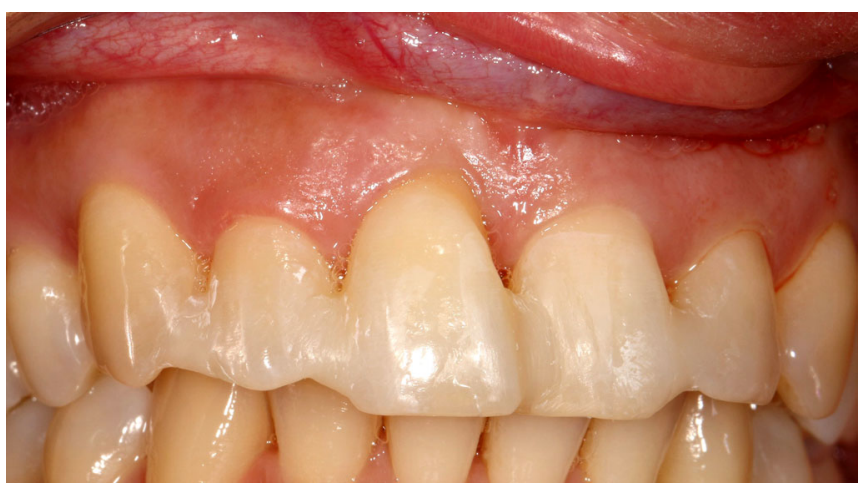


Fig. 2. Initial periodontal status.

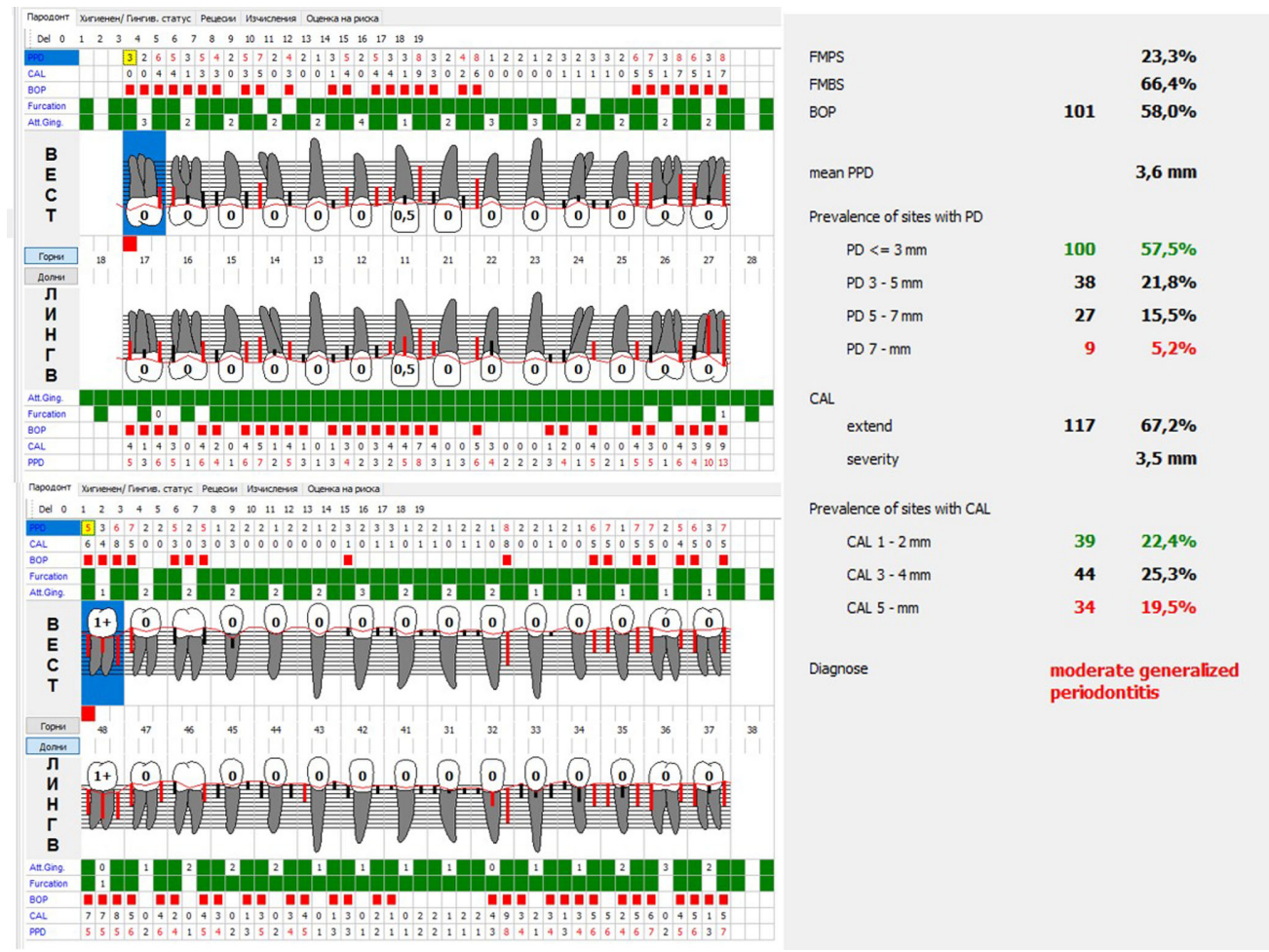

The initial mechanical therapy led to good control of the periodontal infection. The extent of the sites with BoP was reduced to $10,1 \%$. The prevalence of the deep periodontal pockets $(>5 \mathrm{~mm})$ was also reduced significantly to 2 sites $(1,2 \%)$ from 36 sites $(20,7 \%)$, with a single residual deep periodontal defect at right central maxillar incisor with $8 \mathrm{~mm}$ probing depth and $9 \mathrm{~mm}$ clinical attachment loss (Fig. 3 and 4). Due to the existing recession and root exposure of this

tooth, the amount of attached gingiva was reduced (1,5mm) compared to the neighboring teeth $(5 \mathrm{~mm}$ on the right lateral incisor and $4 \mathrm{~mm}$ on the left central incisor, respectively). The right central incisor also showed a Miller grade I mobility, therefore a galss-fiber reinforced composite splint was placed palatal on the maxillary incisors and canines in order to provide the required immobilization of the teeth for the upcoming procedure for periodontal regeneration.

Fig. 3. Periodontal status at re-evaluation.

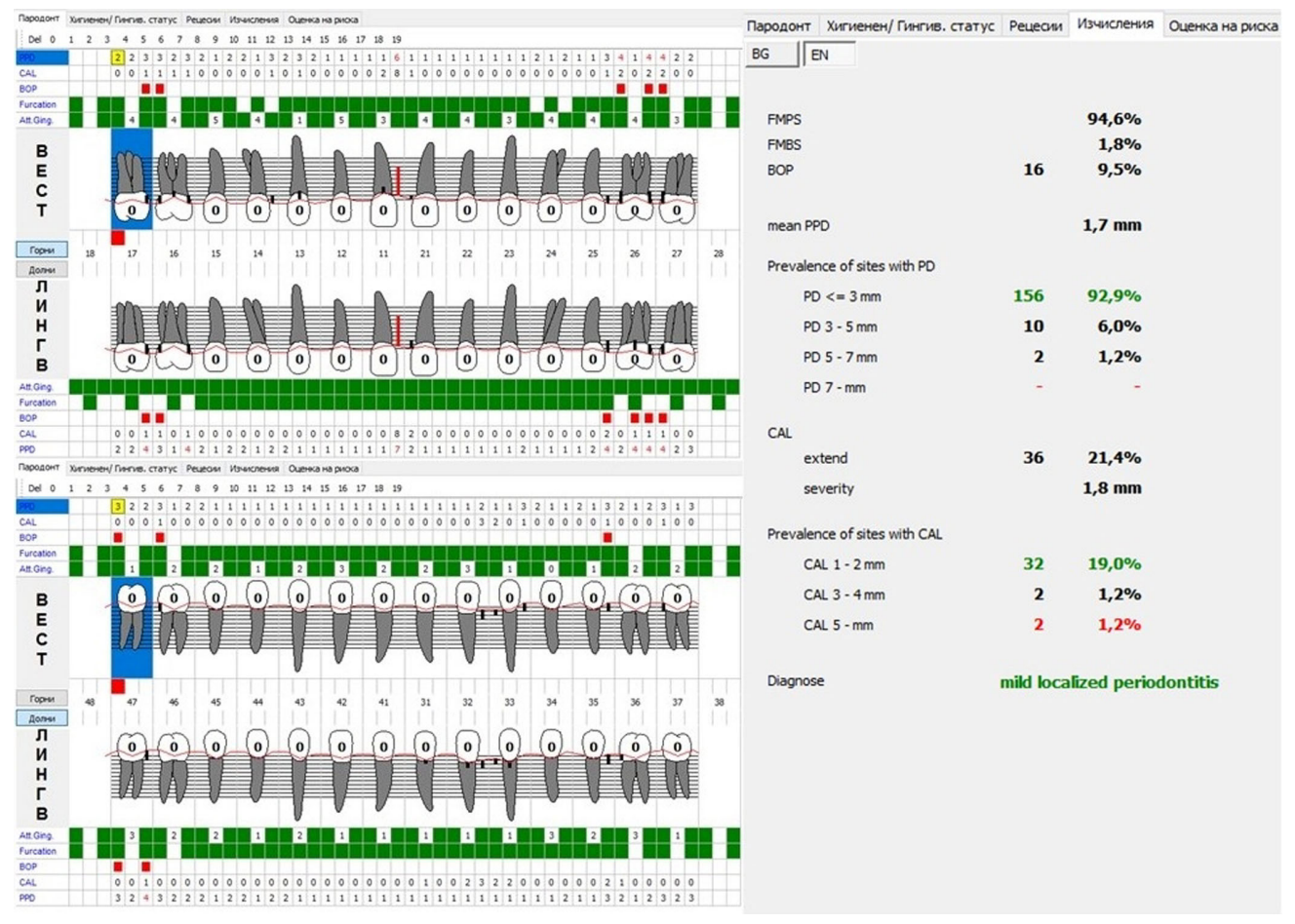


Fig. 4. Residual periodontal pocket at 11 .

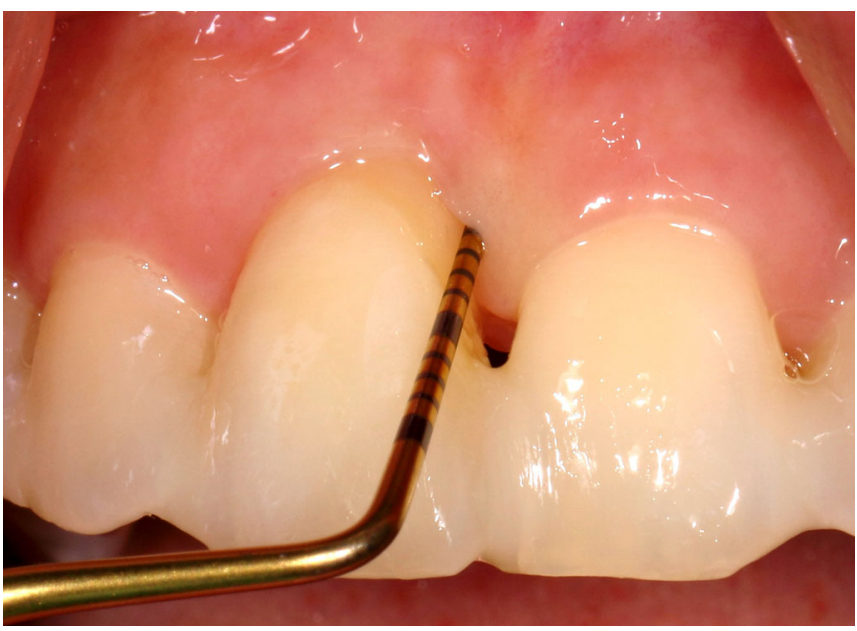

The retro-alveolar x-ray revealed a deep intrabony defect mesial on the central incisor (Fig. 5)
Fig. 5. Retro-alveolar x-ray 11.

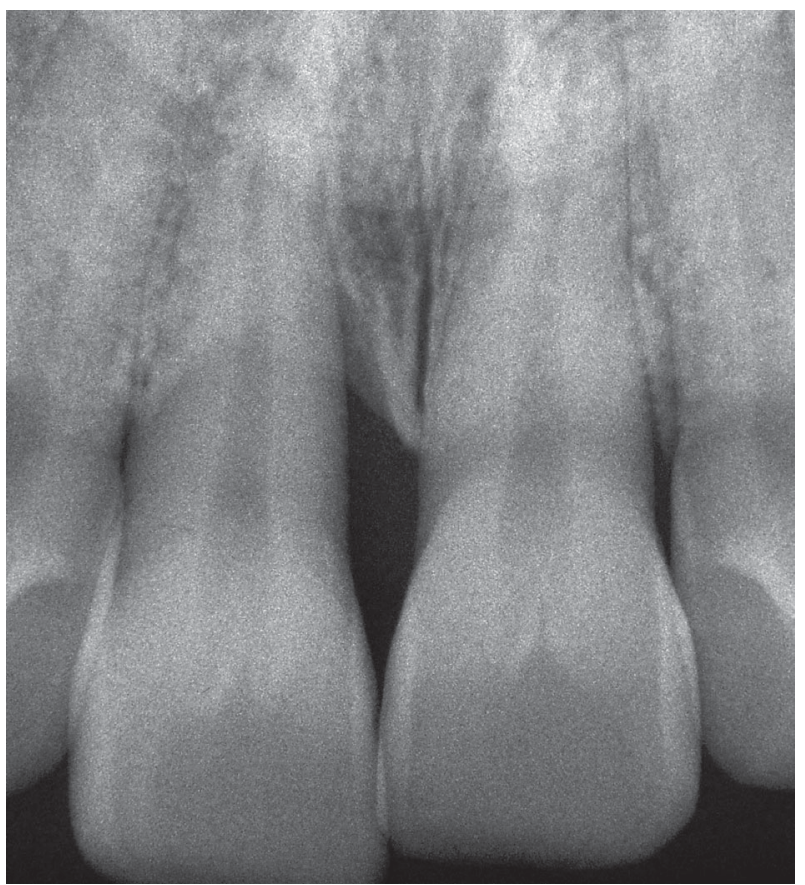

For better diagnosis of the bone defect a CBCT was made (Fig. 6), which revealed a two wall intra osseous defect with a depth of $4,7 \mathrm{~mm}$ and width of $21^{\circ}$. A dehiscence of the buccal alveolar wall was also observed.

Fig. 6. $\mathrm{CBCT}$ analysis.

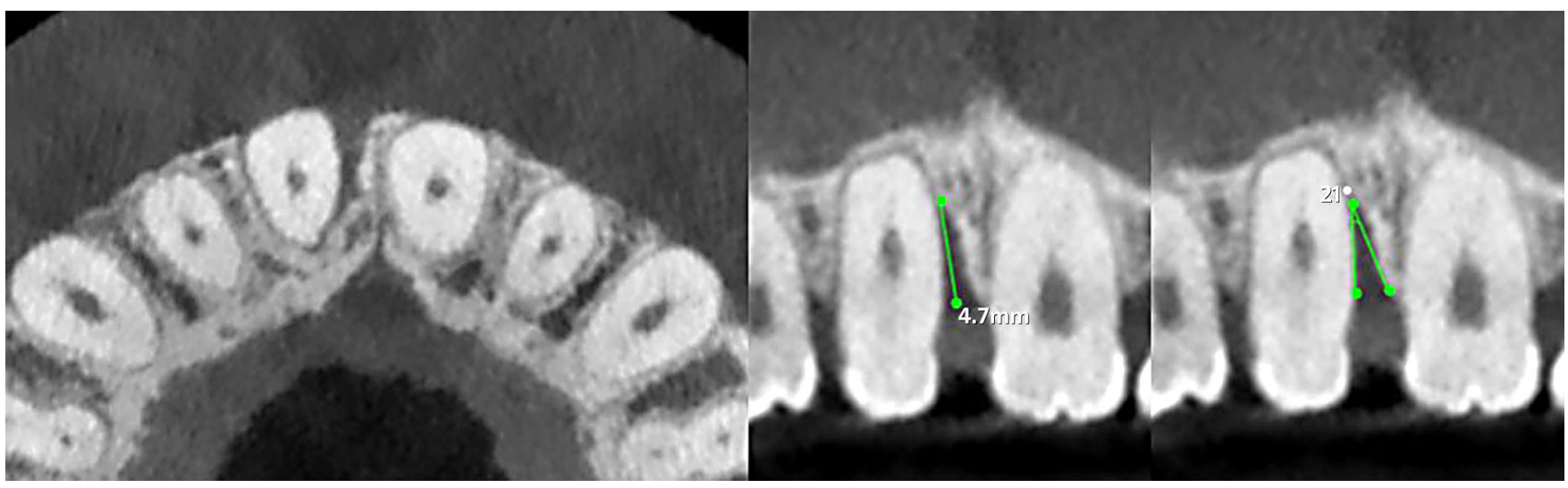

Because of the achieved effective plaque control, good initial healing and proper defect anatomy a regenerative procedure was the procedure of choice. A minimally invasive, single flap technique with buccal access was chosen because of the lacking buccal bony wall of the defect.

The initial incision separated the papillae neighbouring the defect in anatomical and surgical following the rules for multiple recession approach (Fig. 7.) [1].

Fig. 7. Initial incision.

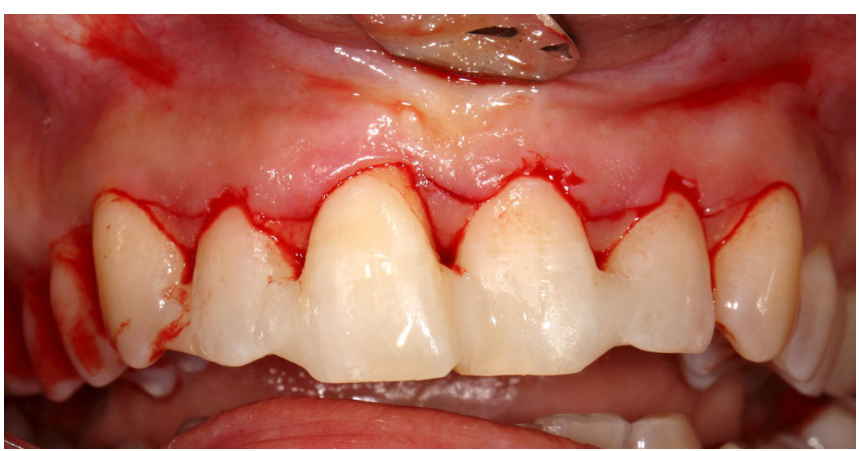


The incisive papillary isthmus was less than $2 \mathrm{~mm}$, so the simplified papilla preservation approach with oblique incision was chosen [2].

A combined thickness buccal flap with sharp incisions in the papillae and full thickness on buccal root and bone surface was applied (Fig. 8).

Fig. 8. Buccal flap.
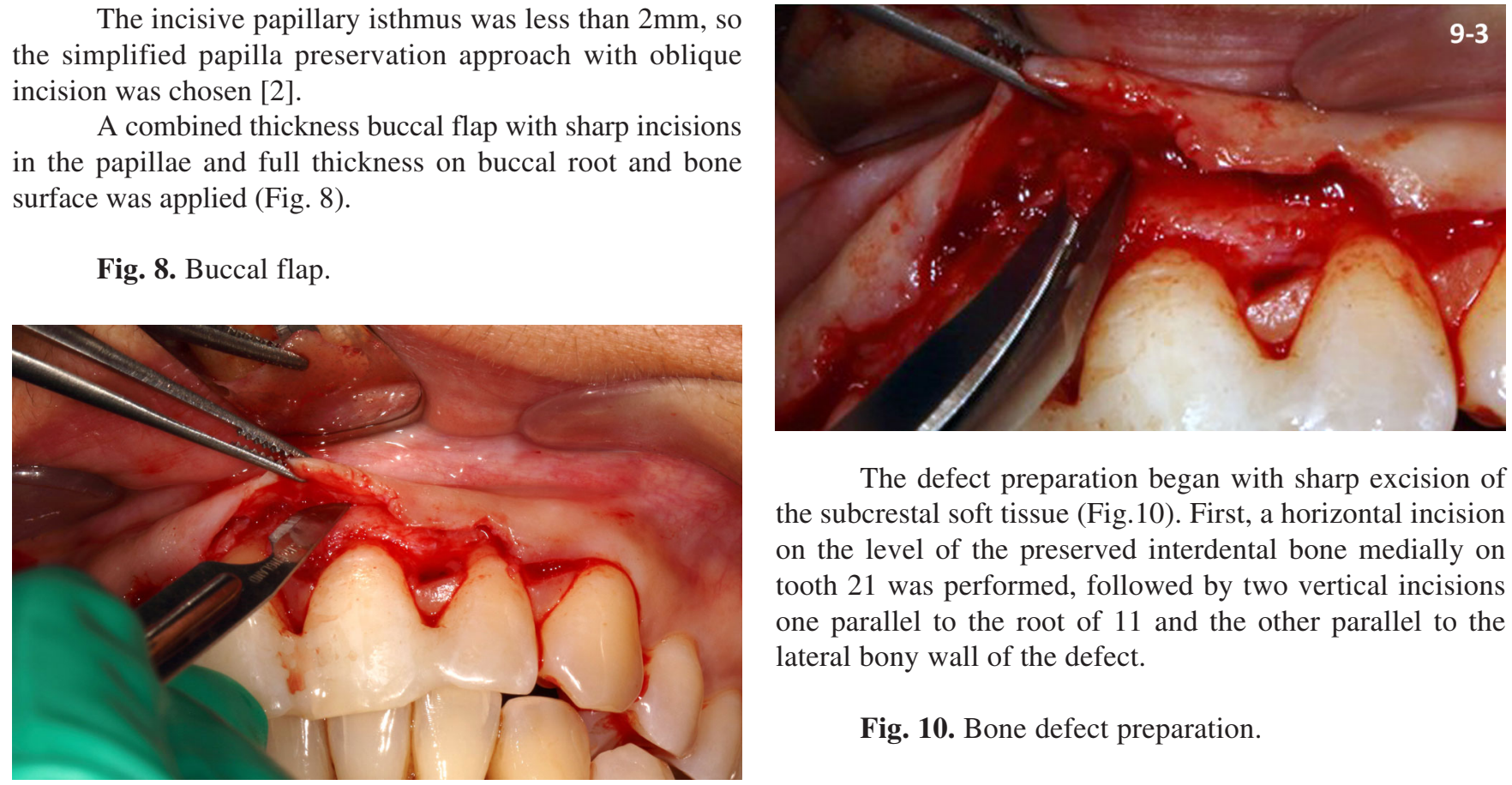

The defect preparation began with sharp excision of the subcrestal soft tissue (Fig.10). First, a horizontal incision on the level of the preserved interdental bone medially on tooth 21 was performed, followed by two vertical incisions one parallel to the root of 11 and the other parallel to the lateral bony wall of the defect.

Fig. 10. Bone defect preparation.

To ensure tension free flap closure a deep and superficial periosteal incisions were performed together with excision of the labial frenulum (Fig. 9).

Fig. 9. Tension free flap preparation.
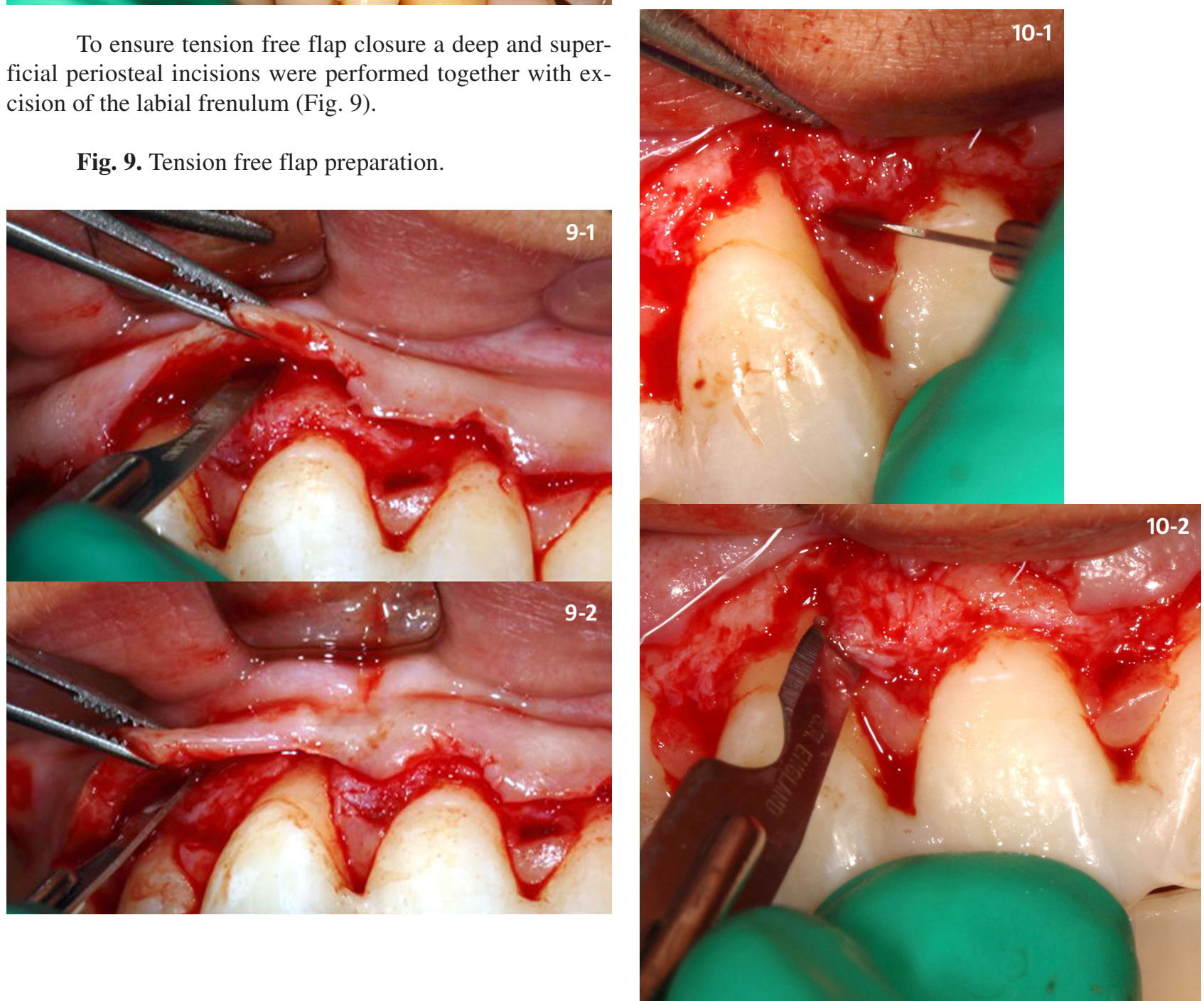

To ensure the integrity of the incisive papilla during the defect debridement, a small papilla pusher was used (Fig. $11)$. 
Fig. 11. Bone defect debridement.

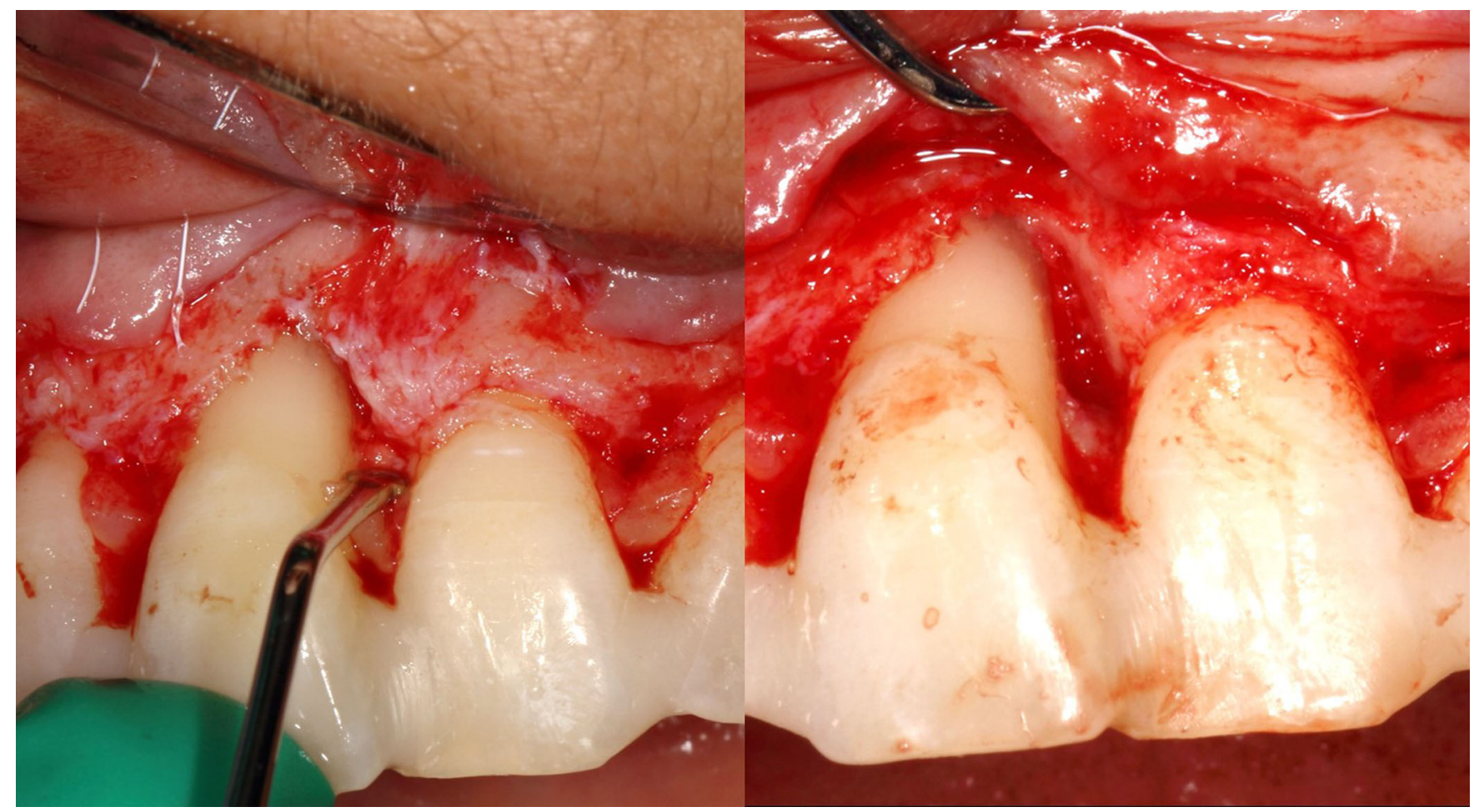

The anatomical papillae were de-epithelized to ensure the good anchorage of the flap in coronal position (Fig.12).

Fig. 12. Anatomical papillae de-epithelization.

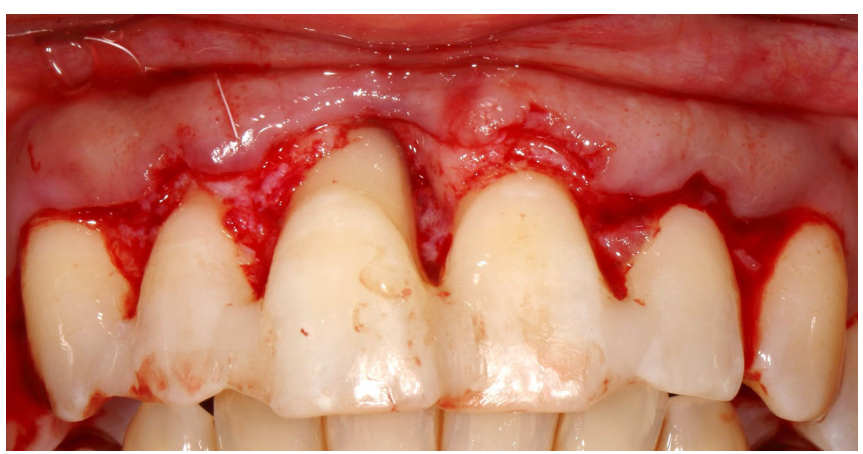

After a thorough defect debridement, an autogenous connective tissue graft was obtained from the palate and deepithelized (Fig.13).

The obtained connective tissue graft was sutured to the remaining periosteum, forming a stable connective tissue wall of the defect, thus ensuring proper protection of the blood clot. To stimulate the regenerative potential of the periodontal cells enamel matrix derivate was applied on the exposed root surface (Fig. 14).

Fig. 13. De-epithelized autogenous connective tissue graft.

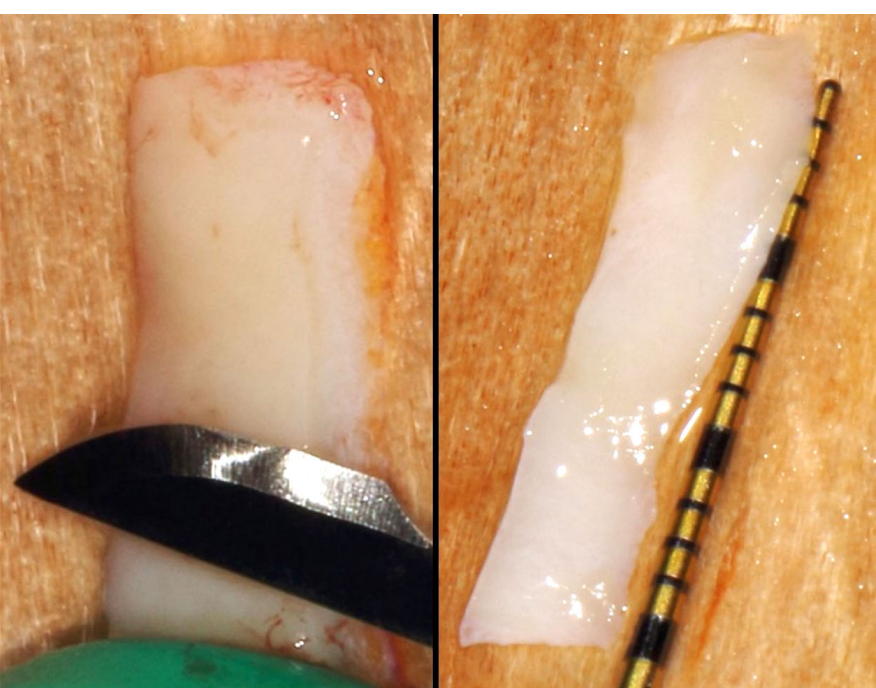


Fig. 14. Suturing of the connective tissue wall and placement of the EMD.

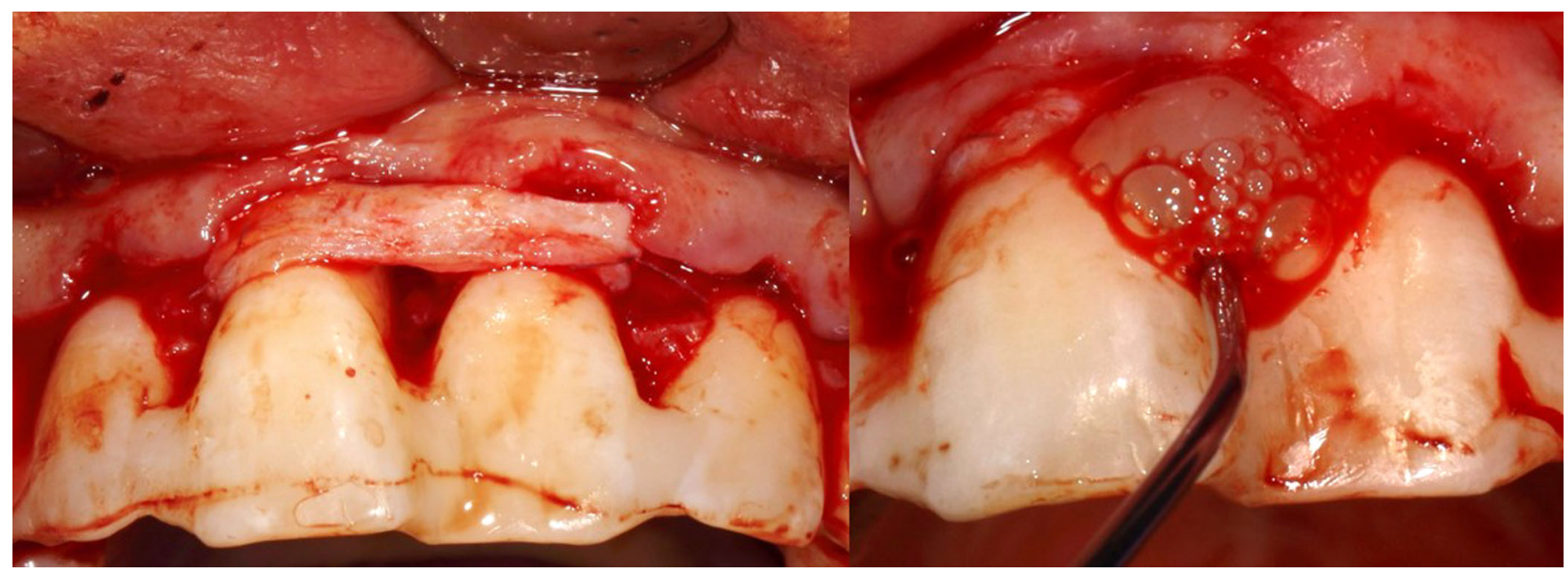

The proper primary closure is of utmost importance for the regenerative process. The flap was sutured in a coronal position using sling sutures on the papillae neighbouring the defect. The incisive papilla was held in coronal position with a horizontal matrass suture. The primary closure of the incisive papilla was ensured with a vertical matrass suture (Fig.15).

Fig. 15. Primary flap closure.

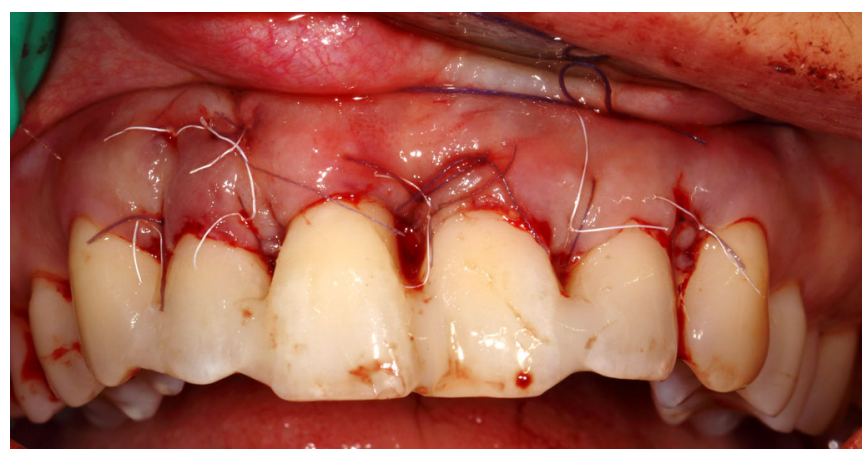

\section{RESULT:}

The healing process went without complications. The flap closure was kept, and no dehiscence was observed, thus providing primary healing process. The sutures were removed on the 14th day after surgery (Fig.16).

Fig. 16. Day 14, before suture removal. Preserves flap closure and primer intention healing.

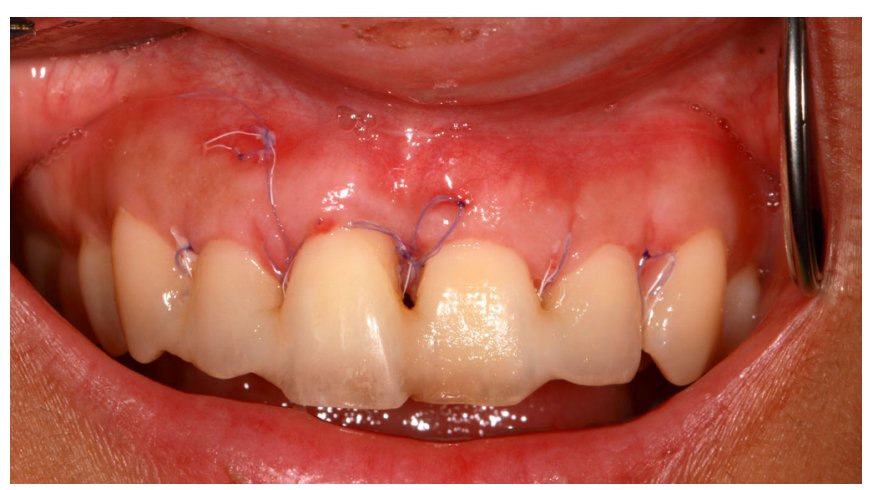

Three months after surgery a fully maturated gingival tissues were observed. The applied connective tissue graft ensured gingival augmentation and adequate amount of attached gingiva on the right central incisor $-6 \mathrm{~mm}$, thus achieving $4,5 \mathrm{~mm}$ new attached gingiva. (Fig.17). Due to the short healing period, periodontal probing was not performed, the rationale is to wait at least 6 months after surgery. The healing process was evaluated on an retro-alveolar x-ray. It showed a complete defect reconstruction with a possible new bundle bone formation and recreation of the periodontal space. As no radiopaque bone substitutes were used, it could be proposed that the achieved result is due to forming of a new periodontal attachment (Fig.18.)

Fig. 17. The third month clinical result.

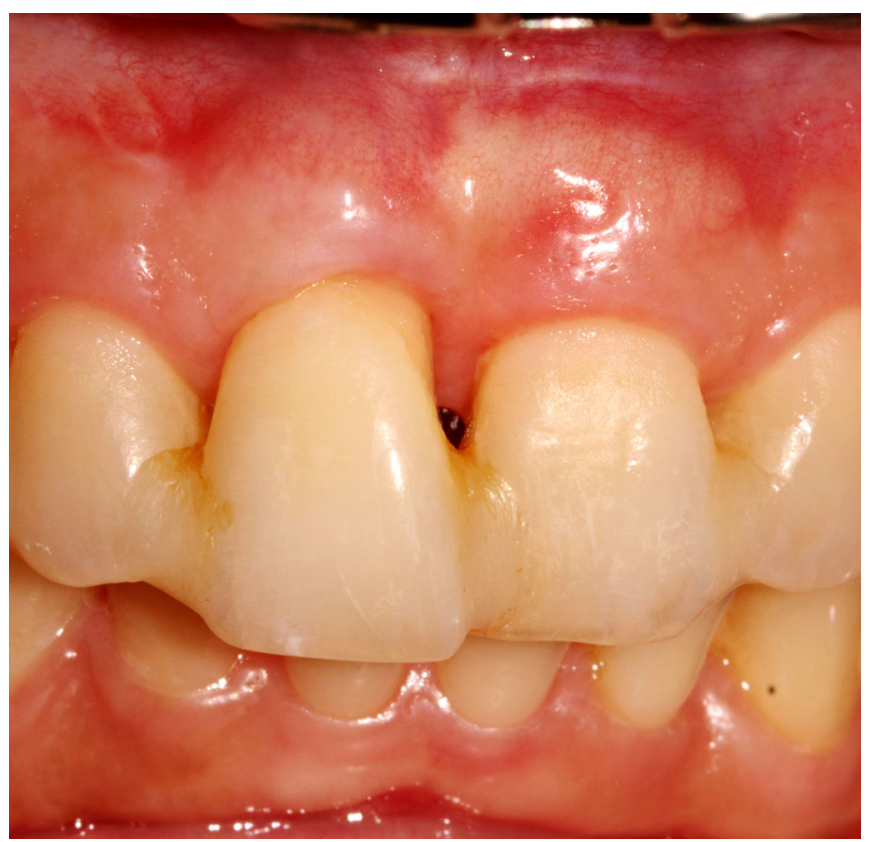


Fig. 18. Third month $x$-ray result.

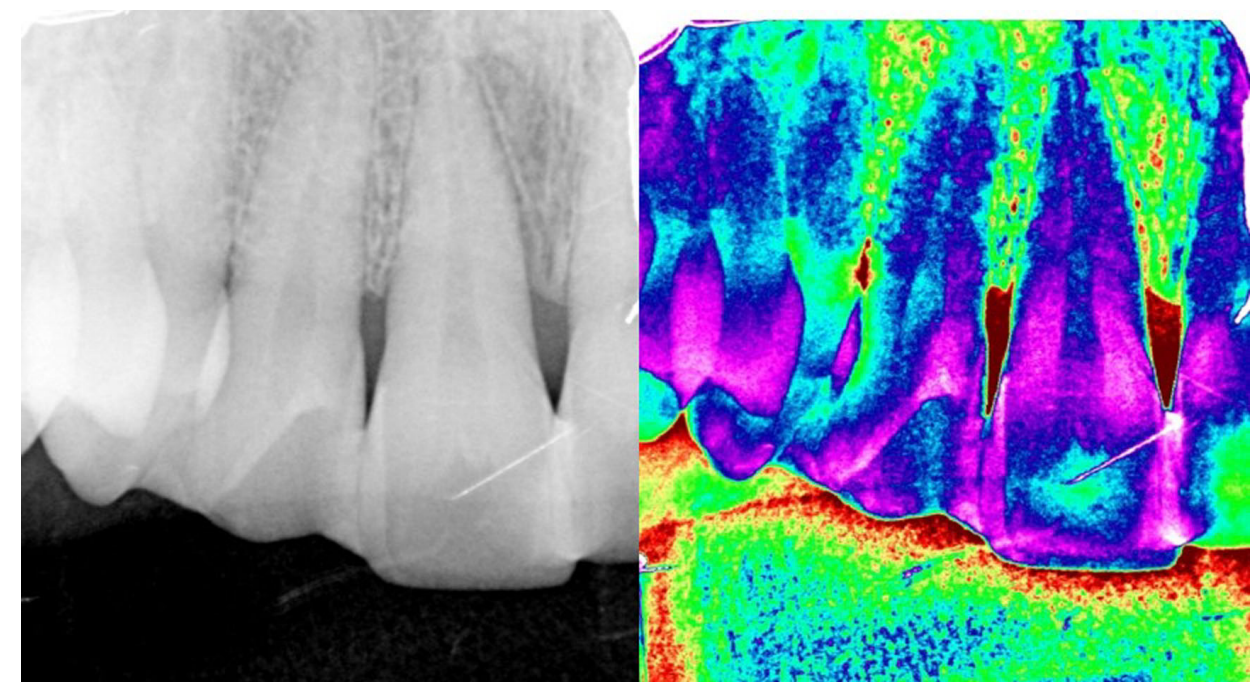

\section{DISCUSSION:}

The classical procedure of choice for intra-bony periodontal defects is the Guided Tissue Regeneration (GTR) approach with the coverage of the bone defect with a barrier membrane aiming space protection for the cells from the periodontal ligament to fill the periodontal defect [3]. Latter studies combined the GTR approach with the placement of bone substitutes in the periodontal defects [4].

In the past decades, a large amount of data was collected regarding the effectiveness of these approaches. The presented clinical results demonstrated positive treatment outcomes regarding clinical attachment gain and probing pocket depth reduction, but these outcomes were very varying between the different studies, moreover, in a significant percentage of the cases a poor treatment outcome was observed due to membrane exposure [5].

In order to surpass these drawbacks of the GTR procedure in the recent years new, minimally invasive approaches for periodontal regeneration were introduced. These new surgical techniques aim a complete tissue preservation in order to achieve and maintain primary closure on top of the applied regenerative material during the critical stages of healing and to save space for blood clot formation and maturation $[6,7]$.

These approaches rely on a single, usually buccal, minimally invasive flap preparation, only in the area of the defect without preparation of the interdental papilla, thus keeping the interdental and oral gingival tissues firmly attached to the underlying bone, thus providing stable anchorage of the flap and good prerequisites for primer intention healing.

The application of these new surgical approaches alone and with bone substitute materials and barrier membranes or enamel matrix derivates (EMD) showed that there are no significant advantages of the adjunctive use of these materials $[8,9,10,11]$.

These contemporary minimal invasive techniques, however, require wide preserved papillary isthmus on the defect site and presence of attached gingiva above the defect bottom to provide good initial healing. In cases with existing soft tissue recessions and insufficiency or lack of attached gingiva, as in the presented case, these techniques can't provide the required coronal advancement of the flap and gingival augmentation. Recent studies reported a postsurgical increase of the buccal soft tissue recessions in cases with buccal bone dehiscence [12].

Recently Zucchelli et al. (2014) presented a new surgical approach, applying the muco-gingival approach for multiple recession coverage for cases with intrabony defects [13].

This new technique showed promising results even in cases with existing gingival recessions, buccal bone dehiscence and insufficient keratinized gingiva [14].

In the presented case the defect analysis of tooth 11 revealed gingival recession, and the presence of buccal bone dehiscence which requires a coronally advanced flap. Moreover, the insufficiency of attached gingiva $(1,5 \mathrm{~mm})$ in the area imposes the application of a connective tissue graft for gingival augmentation. For these reasons, the Connective Tissue Wall technique was chosen as most appropriate to achieve the regenerative outcome.

\section{CONCLUSION:}

In the limitation of the presented case, the applied Connective Tissue Wall technique led to complete clinical healing and new bone formation, which could be proof for periodontal regeneration. The use of the mucogingival approach for multiple recessions increases significantly the indications of the minimally invasive regeneration approaches providing opportunities for better flap handling and anchorage, tension-free flap closure, gingival augmentation and primary intension healing even in cases with gingival recessions and soft tissue insufficiency. Furthermore, the healing process in the presented case was faster than usually observed, with a radiographically shown complete bone healing on the third month after surgery. This result could be a base for further research, to evaluate the potential of this minimally invasive surgical approach to stimulate the healing process. 


\section{REFERENCES:}

1. Zucchelli G, Amore C, Sforza NM, Montebugnoli L, De Sanctis M. Bilaminar techniques for the treatment of recession-type defects. A comparative clinical study. J Clin Periodontol. 2003 Oct;30(10):862-70. [PubMed]

2. Cortellini P, Prato GP, Tonetti MS. The simplified papilla preservation flap. A novel surgical approach for the management of soft tissues in regenerative procedures. Int J Periodontics Restorative Dent. 1999 Dec;19(6):589-99. [PubMed]

3. Nyman S, Lindhe J, Karring T, Rylander H. New attachment following surgical treatment of human periodontal disease. J Clin Periodontol. 1982 Jul;9(4):290-6. [PubMed] [CrossRef]

4. Camargo PM, Lekovic V, Weinlaender M, Nedic M, Vasilic N, Wolinsky LE, et al. A controlled re-entry study on the effectiveness of bovine porous bone mineral used in combination with a collagen membrane of porcine origin in the treatment of intrabony defects in humans. J Clin Periodontol. 2000 Dec;27(12):889-96. [PubMed] [CrossRef]

5. Tonetti MS, Cortellini P, Suvan JE, Adriaens P, Baldi C, Dubravec D, et al. Generalizability of the added benefits of guided tissue regeneration in the treatment of deep intrabony defects. Evaluation in a multi-center randomized controlled clinical trial. J Perio- dontol. 1998 Nov;69(11):1183-92. [PubMed] [CrossRef]

6. Trombelli L, Farina R, Franceschetti G, Calura G. Single-flap approach with buccal access in periodontal reconstructive procedures. $J$ Periodontol. 2009 Feb;80(2):353-60. [PubMed] [CrossRef]

7. Cortellini P, Tonetti MS. Improved wound stability with a modified minimally invasive surgical technique in the regenerative treatment of isolated interdental intrabony defects. J Clin Periodontol. 2009 Feb;36(2):157-63. [PubMed] [CrossRef]

8. Trombelli L, Simonelli A, Pramstraller M, Wikesjö UM, Farina R. Single flap approach with and without guided tissue regeneration and a hydroxyapatite biomaterial in the management of intraosseous periodontal defects. J Periodontol. 2010 Sep;81(9): 1256-63. [PubMed] [CrossRef]

9. Cortellini P, Tonetti MS. Clinical and radiographic outcomes of the modified minimally invasive surgical technique with and without regenerative materials: a randomized-controlled trial in intra-bony defects. J Clin Periodontol. 2011 Apr;38(4):365-73. [PubMed] [CrossRef

10. Farina R, Simonelli A, Minenna L, Rasperini G, Trombelli L. Single-flap approach in combination with enamel matrix derivative in the treatment of periodontal intraosseous defects. Int J Periodontics Restorative Dent. 2014 Jul-Aug;34(4):497-506. [PubMed] [CrossRef]

11. Schincaglia GP, Hebert E, Farina R, Simonelli A, Trombelli L. Single versus double flap approach in periodontal regenerative treatment. J Clin Periodontol. 2015 Jun;42(6):557-66. [PubMed] [CrossRef]

12. Farina R, Simonelli A, Minenna L, Rasperini G, Schincaglia GP, Tomasi C, Trombelli L. Change in the Gingival Margin Profile After the Single Flap Approach in Periodontal Intraosseous Defects. J Periodontol. 2015 Sep;86(9): 1038-46. [PubMed] [CrossRef]

13. Zucchelli G, Mazzotti C, Tirone F, Mele M, Bellone P, Mounssif I. The connective tissue graft wall technique and enamel matrix derivative to improve root coverage and clinical attachment levels in Miller Class IV gingival recession. Int J Periodontics Restorative Dent. 2014 Sep-Oct;34(5):601-9. [PubMed]

14. Trombelli L, Simonelli A, Minenna L, Rasperini G, Farina R. Effect of a Connective Tissue Graft in Combination With a Single Flap Approach in the Regenerative Treatment of Intraosseous Defects. J Periodontol. 2017 Apr;88(4):348-356. [PubMed] [CrossRef]

Please cite this article as: Kotsilkov K. Minimally invasive single flap approach with connective tissue wall for periodontal regeneration. J of IMAB. 2017 Jul-Sep;23(3):1673-1680. DOI: https://doi.org/10.5272/jimab.2017233.1673

Received: 20/05/2017; Published online: 04/09/2017

\section{Address for correspondence:}

Kamen Kotsilkov, DDS, PhD -Associate Professor, Department of Periodontology, Faculty of Dental Medicine, Medical University - Sofia,

1, St. Georgi Sofiiski str., Sofia, Bulgaria.

Private Practice: Dental Clinic Kotsilkovi, 24 Vidini kuli str., Sofia, Bulgaria.

E-mail: kamenkotsilkov@gmail.com 